Article

\title{
Advanced Glycation End Product (AGE)-AGE Receptor (RAGE) System Upregulated Connexin43 Expression in Rat Cardiomyocytes via PKC and Erk MAPK Pathways
}

\author{
Lu Yu, Yanbo Zhao, Shengjie Xu, Fang Ding, Chongying Jin, Guosheng Fu and \\ Shaoxiang Weng *
}

Department of Cardiovascular Medicine, Sir Run Run Shaw Hospital, College of Medicine, Zhejiang University, Hangzhou 310016, China; E-Mails: jyulu@sina.com.cn (L.Y.); zyboshimly@163.com (Y.Z.); xusj@zju.edu.cn (S.X.); dingdinghello@sina.com (F.D.); jincy_lv@163.com (C.J.); fuguoshengvip@sina.com (G.F.)

* Author to whom correspondence should be addressed; E-Mail: wengshaoxiangvip@sina.cn; Tel./Fax: +86-571-8600-6248.

Received: 21 August 2012; in revised form: 19 December 2012 / Accepted: 8 January 2013 / Published: 24 January 2013

\begin{abstract}
The remodeling of cardiac gap junction contributes to the arrhythmias in a diabetic heart. We previously reported that high glucose reduced $\mathrm{Cx} 43$ protein level in neonatal rat cardiomyocytes. But, the effect and mechanisms of advanced glycation end product (AGE) on Cx43 expression still remain unclear. In this study, we measured the AGE receptor (RAGE) and Cx43 expression by immunohistochemisty in AGE-infused Sprague-Dawley (SD) rats. In vitro, the Cx43 and RAGE levels were detected in AGE-treated cardiomyocytes by Western blot and real-time RT-PCR. The function of cells coupling was measured by Scrap loading dye transfer assay. Our results showed that the AGE-infused rat hearts exhibited increased cardiac RAGE and Cx43, as well as Cx43 redistribution. In cultured cardiomyocytes, AGE elevated RAGE expression in a time- and dose-dependent manner. Cx43 protein and mRNA levels were upregulated by AGE (200 mg/L, $24 \mathrm{~h}$ ), but the gap junction function was not enhanced. RAGE-targeted knock-down or the addition of PKC, and Erk inhibitors abolished the effect of AGE on Cx43. Therefore, AGE-RAGE system might elevate $\mathrm{Cx} 43$ expression in rat cardiomyocytes by activating PKC and Erk MAPK pathways, and it also enhanced $\mathrm{Cx} 43$ redistribution in vivo, which might contribute to the arrhythmias in diabetes.
\end{abstract}


Keywords: advanced glycation end product; connexin43; cardiomyocytes; diabetes

\section{Introduction}

Diabetes contributes to the high incidence of cardiac arrhythmias, including atrial or ventricular fibrillation and sudden death [1]. Recent studies began to focus its mechanisms and indicated that altered cardiac gap junction expression or function could lead to conduction disturbance and arrhythmias [2,3]. It has been demonstrated that $\mathrm{Cx} 43$ is the major connexin in ventricular cardiomyocytes, whereas $\mathrm{Cx} 40$ and $\mathrm{Cx} 45$ is relatively co-expressed in atrial myocytes and the conduction system [4]. Therefore, the quantity alteration or redistribution of $\mathrm{Cx} 43$ could provide an arrhythmogenic substrate for various arrhythmias.

Hyperglycemia is regarded as a major initiator for cardiac complications in diabetes [5]. In our previous study [6], we demonstrated that high glucose could reduce $\mathrm{Cx} 43$ expression in neonatal rat cardiomyocytes. But, in some other recent studies, the amount of cardiac Cx43 was up- or down-regulated in streptozotocin (STZ)-induced diabetic rat model [7-9]. Therefore, we could not exclude the possibility that the discordant results might be due to other factors other than high glucose alone, such as advanced glycation end product (AGE). AGE are the products of nonenzymatic glycoxidation of proteins accumulated in diabetes and participate in various cardiovascular diseases, mainly through their receptor (RAGE) [10,11]. Recent studies have reported that the AGE and RAGE-ligand interaction was involved in the pathogenesis of cardiomyocytes injury induced by hopoxia/reoxygenation [12], and it also contributed to calcium handling impairment [13] or the onset of diabetic cardiomyopathy [14]. The results indicated the pathogenic effect of the AGE-RAGE system on cardiomyocytes. But, direct evidence is still absent for $\mathrm{Cx} 43$ expression under AGE treatment, which might lead to cardiac $\mathrm{Cx} 43$ remodeling in diabetic models.

It was also demonstrated that $\mathrm{Cx} 43$ distribution could be an important factor for electrical conduction velocity and vulnerability limits [15], which was associated with cardiac arrhythmias. Disorganized connexins and gap junction could not form junction channels [16], and enhanced $\mathrm{Cx} 43$ lateralization may reduce cell excitability [17]. To date, several studies [17,18] have pointed out the Cx43 redistribution in a diabetic heart. But the effect of AGE alone still needs more investigation.

Therefore, in the present study, we aimed to explore the effect and mechanisms of AGE on cardiac Cx43/RAGE expression in rat cardiomyocytes and their possible redistribution in vivo models.

\section{Results and Discussion}

\subsection{Results}

\subsubsection{The Cardiac RAGE and Cx43 Expressions in AGE-Infused Rats}

The RAGE and Cx43 staining in BSA- or AGE-infused rat hearts were performed by immunohistochemisty. As displayed in Figure 1, RAGE proteins were expressed abundantly in AGE-infused rat heart, while they were rarely observed in BSA-infused rat or control group. Labeling of cardiac $\mathrm{Cx} 43$ also exhibited a significant upregulation and redistribution, which scattered and 
lateralized along cardiomyocytes. No significant $\mathrm{Cx} 43$ staining difference was seen in BSA-infused rat heart compared to control group. The result indicated the upregulation effect of AGE on RAGE and Cx43 protein levels in vivo models.

Figure 1. The advanced glycation end product (AGE)-AGE receptor (RAGE) and Cx43 staining in rat heart tissue. (A) The RAGE and Cx43 expression detected by immuohistochemisty; (B) Quantity analysis of staining assessed by ImageJ software. bovine serum albumin (BSA): BSA-infused rat $(40 \mathrm{mg} / \mathrm{kg} / \mathrm{d})$; AGE: AGE-infused rat (40 mg/kg/d). Black arrow: RAGE; White arrow: Cx43. Bar: $100 \mu \mathrm{M} .{ }^{*} p<0.05$ vs. control.
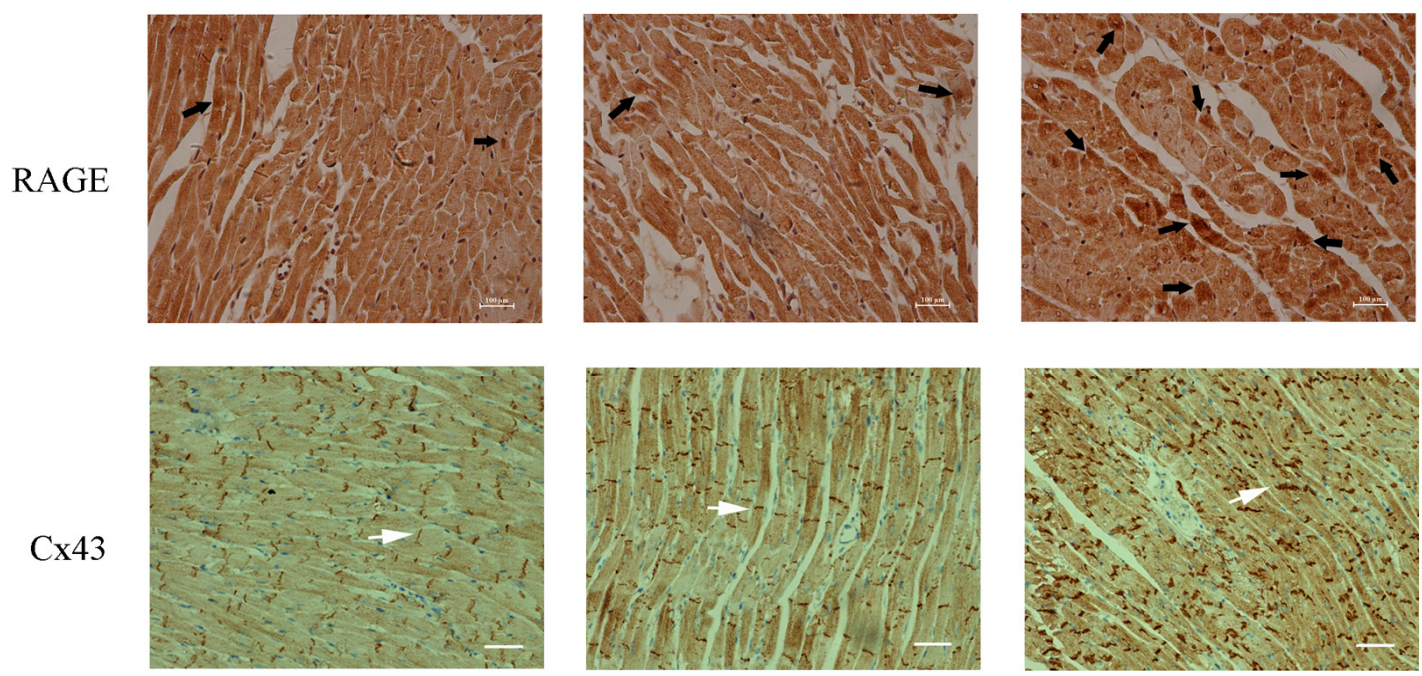

A.

$$
\text { Control }
$$

BSA

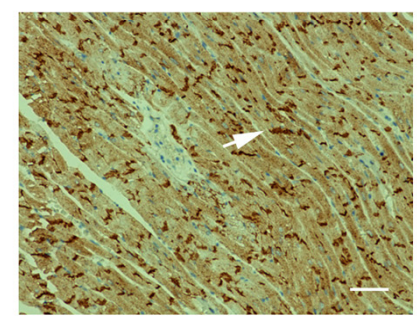

AGE

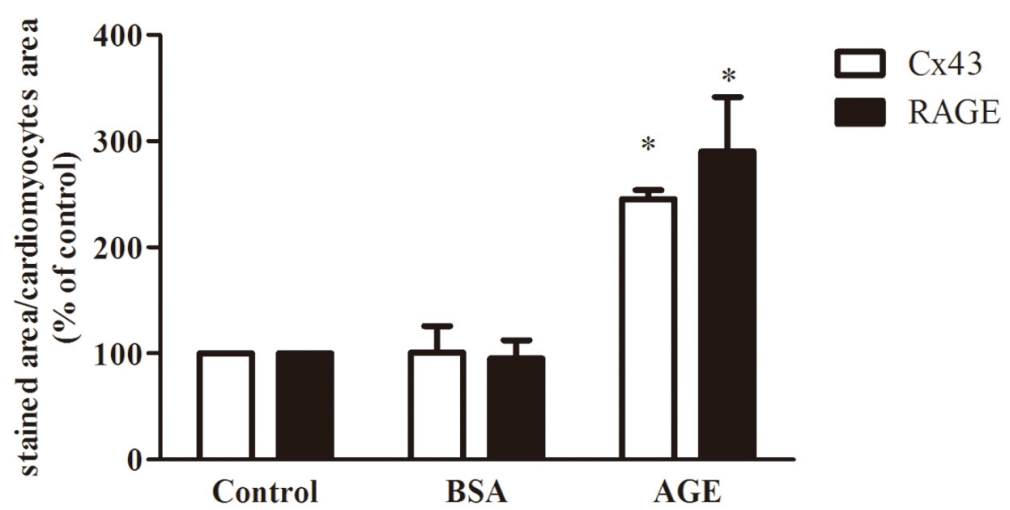

B.

\subsubsection{Effects of AGE on Cell Viability}

In in vitro study, the cultured neonatal rat cardiomyocytes were exposed to AGE treatment. We measured the cell viability under AGE incubation by MTT assay. As a recent study reported [19], cells were treated with $0,50,100$ and $200 \mathrm{mg} / \mathrm{L}$ AGE for $24 \mathrm{~h}$ or $0,6,12,24$ and $48 \mathrm{~h}$ of AGE at a concentration of $200 \mathrm{mg} / \mathrm{L}$. In Figure 2, it showed that AGE had no significant cytotoxic effect on cardiomyocytes. 
Figure 2. Effect of AGE on the cell viability determined by MTT assay. (A) Cells were treated with AGE at the concentration of 50, 100 and $200 \mathrm{mg} / \mathrm{L}$ for $24 \mathrm{~h}$; (B) Cells were treated with AGE at $200 \mathrm{mg} / \mathrm{L}$ for $6,12,24$ and $48 \mathrm{~h}$ respectively. $n=5$ wells in each individual experiment. $* p<0.05 v s$. control; Data are mean $\pm \mathrm{SD}$.


\subsubsection{AGE Upregulated RAGE Expression in Cardiomyocytes}

To investigate the effect of AGE on RAGE expression in vitro, cells were exposed to BSA (200 mg/L) or AGE at various concentrations $(50,100,200 \mathrm{mg} / \mathrm{L}$ ) for $24 \mathrm{~h}$. The RAGE protein level was elevated in a dose-dependent manner and peaked at $200 \mathrm{mg} / \mathrm{L}$ in cells treated by AGE, whereas BSA alone showed no significant effect on it (Figure 3A). Cells were then treated by AGE at $200 \mathrm{mg} / \mathrm{L}$ for $6,12,24$ and $48 \mathrm{~h}$. RAGE protein also increased in a time-dependent manner and peaked at $24 \mathrm{~h}$ (Figure 3B). The real-time RT-PCR also showed that the RAGE mRNA level was elevated by AGE (200 mg/L) treatment for $24 \mathrm{~h}$ and remained unchanged in BSA-treated cardiomyocytes (Figure 3C).

Figure 3. The effect of AGE on RAGE expression in cardiomyocytes. (A) AGE upregulated the RAGE protein expression in a dose-dependent manner and peaked at $200 \mathrm{mg} / \mathrm{L}$; (B) AGE increased the RAGE protein expression in a time-dependent manner and peaked at $24 \mathrm{~h}$; (C) RAGE mRNA level was upregulated by AGE (200 mg/L) treatment for $24 \mathrm{~h}$. $* p<0.05 v s$. control, BSA (200 mg/L); \# $p<0.05 v s$. AGE (50 mg/L, $100 \mathrm{mg} / \mathrm{L})$ or AGE (6h, 12h, $48 \mathrm{~h})$; Data are mean $\pm \mathrm{SD}$.
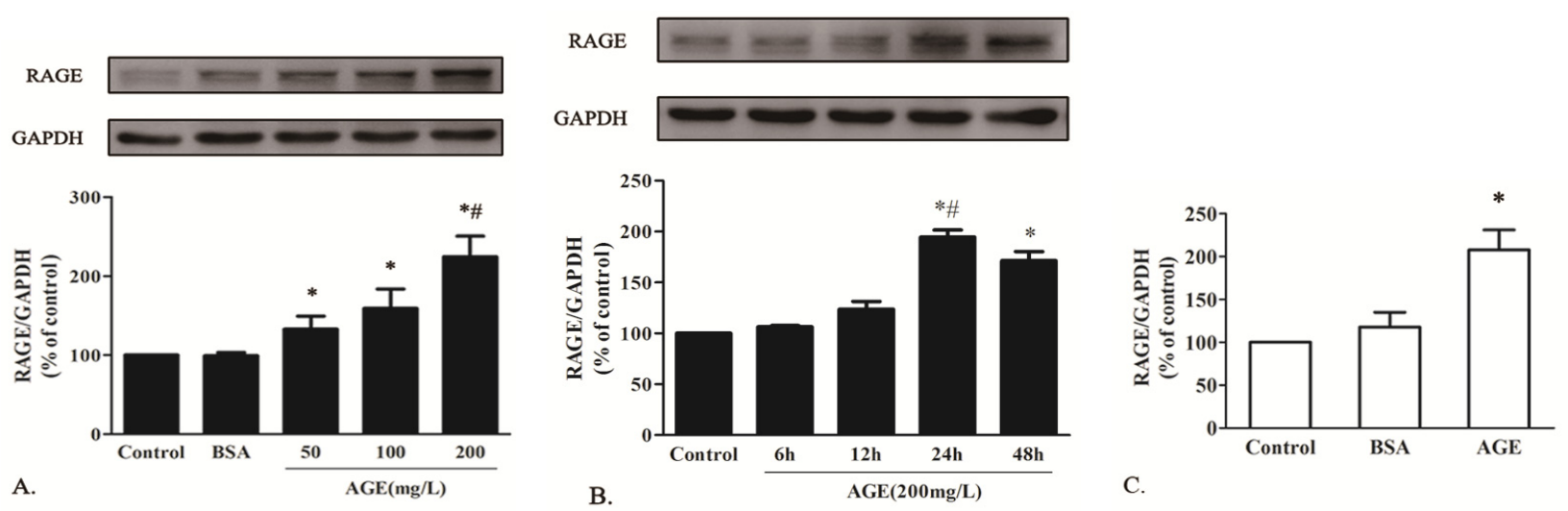

2.1.4. The Effects of AGE on Cx43 Expression and GJIC Function in Cardiomyocytes

As AGE increased RAGE expression most effectively at $200 \mathrm{mg} / \mathrm{L}$ for $24 \mathrm{~h}$, the same concentration and incubation time of AGE or BSA were used in detecting cardiac $\mathrm{Cx} 43$. The Cx43 antibody 
recognizes three bands by Western blots, which consists of a nonphosphorylated form (P0) at $41 \mathrm{kDa}$ and two phosphorylated forms (P1, P2), ranging in size between 43 and $45 \mathrm{kDa}$. As shown in Figure 4A, AGE upregulated total $\mathrm{Cx} 43$ protein expression, including P0, P1 and P2, whereas BSA alone showed no significant effect. The similar change of $\mathrm{Cx} 43$ mRNA level could also be observed by real-time RT-PCR (Figure 4B).

Therefore, our results indicated that AGE could elevate RAGE/Cx43 expression both in vivo and in vitro. Unexpectedly, however, compared to the control group, cells treated by AGE ( $200 \mathrm{mg} / \mathrm{L}$, $24 \mathrm{~h}$ ) showed no significant change in the distance of the dye transferred from the scrape margin (Figure 4C-E). It suggested that the AGE-elevated $\mathrm{Cx} 43$ might not exert their activity or enhance cellular coupling in cardiomyocytes.

Figure 4. The effect of AGE on $\mathrm{Cx} 43$ expression and gap junctional intercellular communication (GJIC) function. (A) $\mathrm{Cx} 43$ protein (P0, P1, P2) expression was upregulated by AGE $(200 \mathrm{mg} / \mathrm{L})$ treatment for $24 \mathrm{~h}$; (B) Cx43 mRNA level was upregulated by AGE $(200 \mathrm{mg} / \mathrm{L})$ treatment for $24 \mathrm{~h}$. (C) and (D) showed effect of AGE on the GJIC function assessed by Scrape loading dye transfer assay; (E) The quantity analysis of dye transfer distance in each group. * $p<0.05$ vs. control, BSA (200 mg/L); White arrow: scrape line; Data are mean \pm SD.
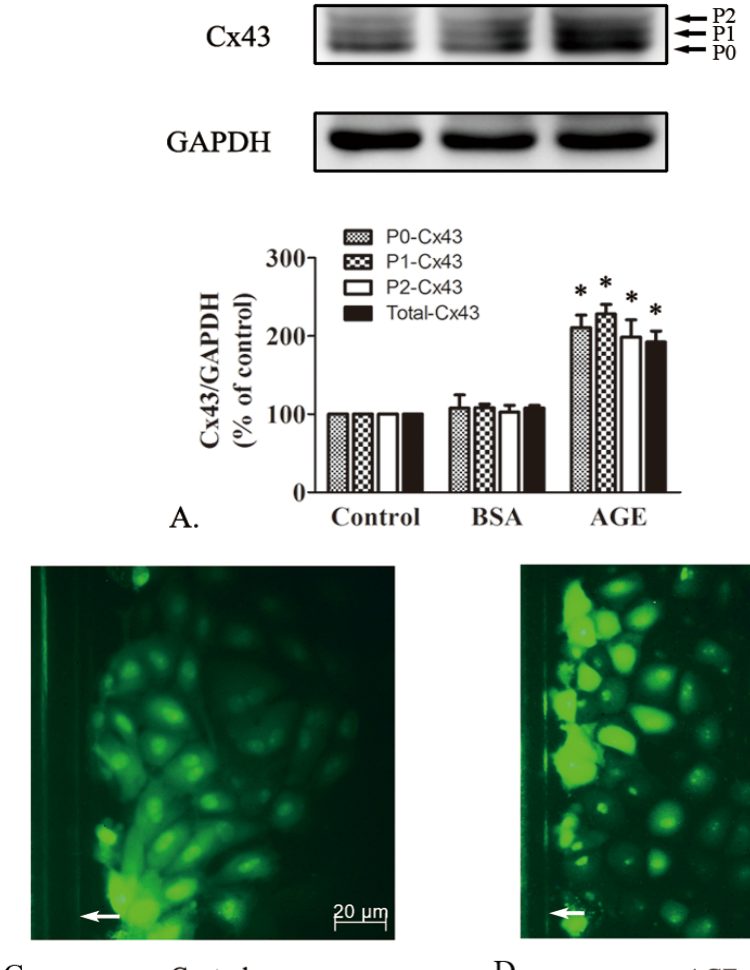

C.

Control

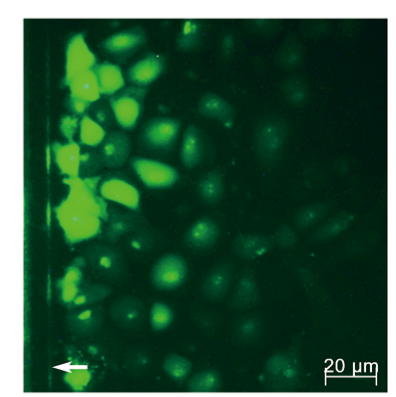

D.
AGE
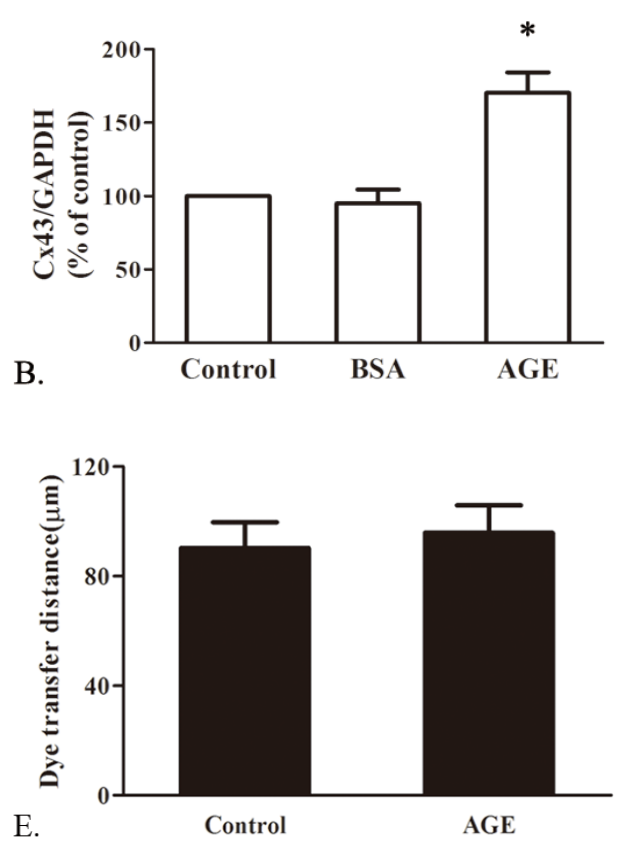

\subsubsection{AGE Increased Cx43 Expression via AGE-RAGE Pathway}

According to the in vivo and in vitro results, AGE significantly increased cardiac $\mathrm{Cx} 43$ expression. But, the mechanisms were still unclear. As RAGE has been indicated as an interaction ligand of AGE in exerting various pathogenic effects, we investigated whether RAGE was involved in this effect. By using siRNA technology, we knocked down the RAGE expression, which was identified by Western 
blot and real-time RT-PCR (Figure 5A). As seen in Figure 5B, Cx43 was not elevated by AGE incubation in cells with RAGE knocked down, whereas it could still be upregulated in cardiomyocytes with scrambled siRNA treatment. The result suggested that AGE elevated Cx43 level in cardiomyocytes mainly by RAGE activation.

Figure 5. The effect of AGE on $\mathrm{Cx} 43$ expression in cardiomyocytes with RAGE knocked down. (A) The identification of RAGE expression knocked down with small interfering (siRNA) assessed by Western blot and real-time polymerase chain reaction (PCR); (B) The effect of AGE on Cx43 protein in cardiomyocytes with or without RAGE knocked down. $* p<0.05$ vs. Scr (Scrambled siRNA); siRNA: RAGE-targeted siRNA. Data are mean \pm SD.

RAGE

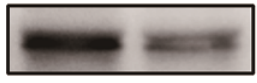

GAPDH
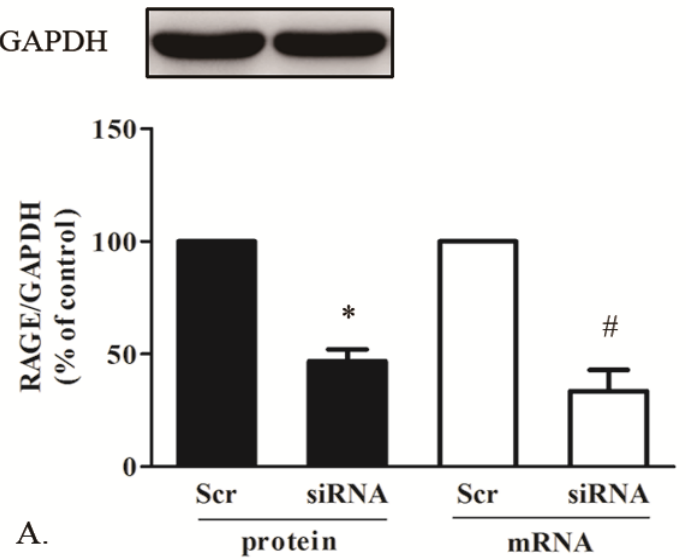

$\mathrm{Cx} 43$

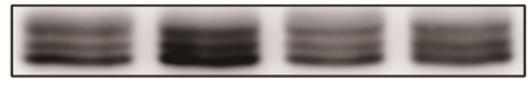

GAPDH
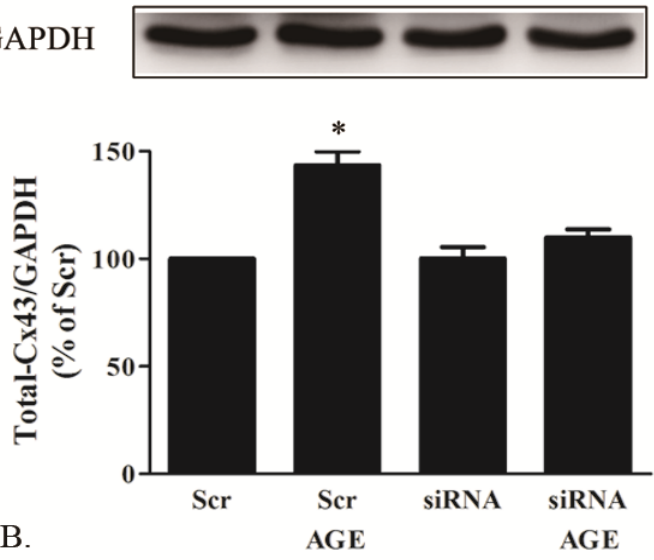

\subsubsection{AGE Activated MAPK Pathway}

Activation of RAGE induced by AGE engages various signal transduction pathways, among which MAPKs act as a major one in response to extracellular signals [20]. To investigate AGE-induced signaling pathways, the phosphorylation levels of MAPK family proteins (Erk, p38, JNK) were measured in cardiomyocytes treated by AGE at $200 \mathrm{mg} / \mathrm{L}$ for 7.5, 15, 30, 60 and $120 \mathrm{~min}$. As seen in Figure 6A-C, AGE activated the time-dependent phosphorylation level of JNK, Erk and p38 assessed by Western blot.

Cells were then co-incubated by AGE $(200 \mathrm{mg} / \mathrm{L})$ or AGE with the presence of JNK MAPK inhibitor SP600125 $(20 \mu \mathrm{M})$, Erk MAPK inhibitor PD98059 $(20 \mu \mathrm{M})$ or p38 MAPK inhibitor SB203580 $(10 \mu \mathrm{M})$ for $24 \mathrm{~h}$. All the inhibitors were added to cells $30 \mathrm{~min}$ before AGE treatment. Our previous study had demonstrated that MAPK inhibitors alone did not affect cardiac $\mathrm{Cx} 43$. In this present work, we observed that only PD98059 totally abolished the AGE-induced Cx43 upregulation (Figure 6D). Although SB203580 partly downregulated the total Cx43 level increased by AGE, it only alleviated the upregulation of $\mathrm{Cx} 43$ in $\mathrm{P} 2$ band, whereas it had no effect on the increased expression of P0- or P1-Cx43 (statistical analysis data not shown). Therefore, it could be supposed that AGE elevated Cx43 expression partly by Erk MAPK pathway. 
Figure 6. AGE elevated time-dependent phosphorylation levels of JNK (A); Erk (B) and P38 MAPK (C) in cardiomyocytes determined by Western blot. (D) Western blot analysis of Cx43 expression in AGE-treated cardiomyocytes with the presence of MAPK inhibitors. $* p<0.05$ vs. control; $\# p<0.05$ vs. AGE; Data are mean \pm SD.

P-JNK

JNK

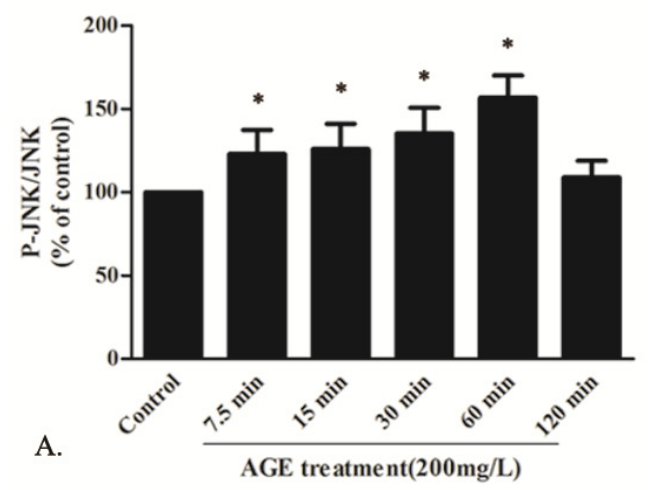

P-P38

P38
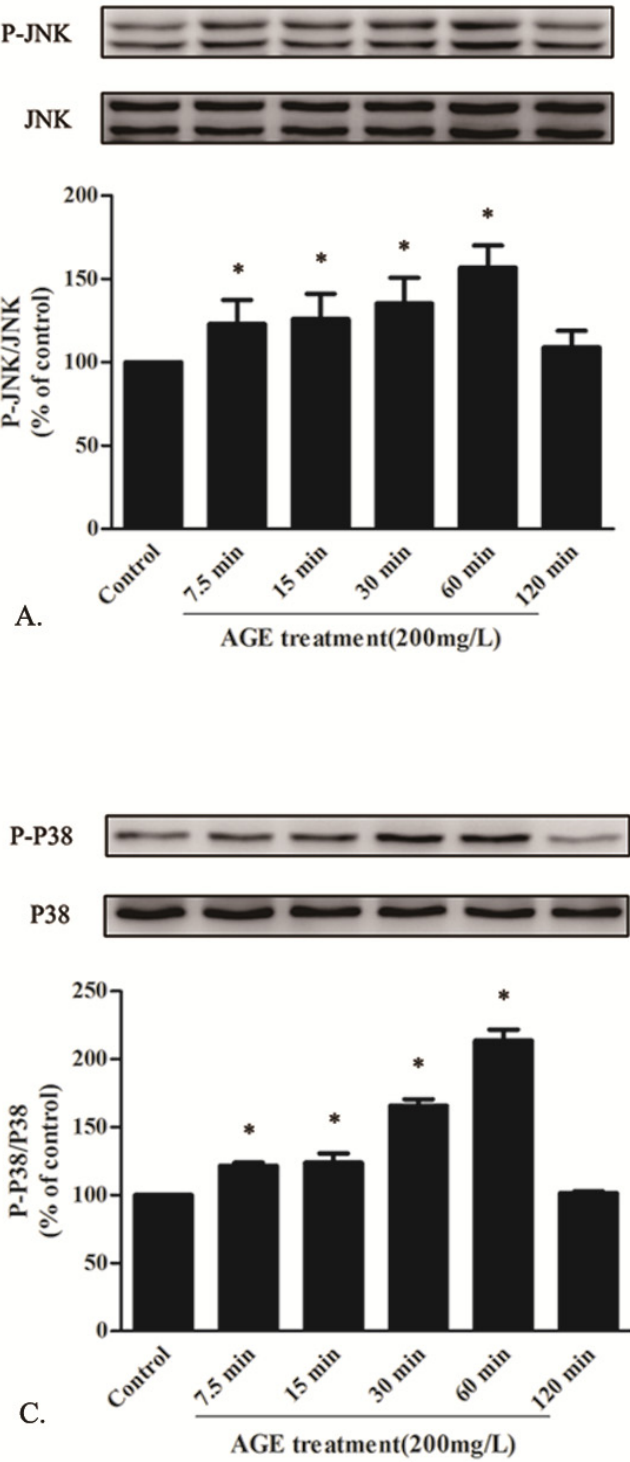

P-Erk

Erk

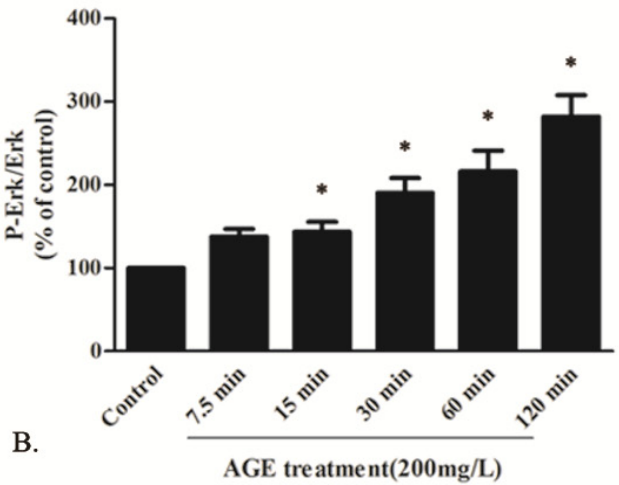

$\mathrm{Cx} 43$

GAPDH

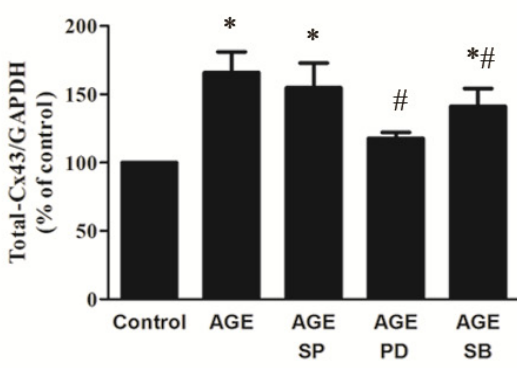

D.
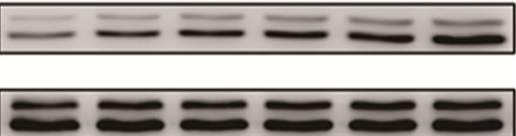

AGE treatment $(200 \mathrm{mg} / \mathrm{L})$
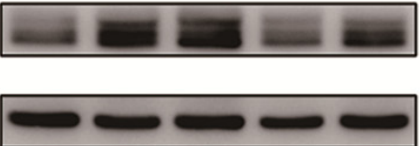

\subsubsection{AGE Activated PKC Pathway}

In the progression of diabetes, the PKC pathway is considered as an important signal transduction pathway leading to structural or functional changes in cardiomyocytes. PKC- $\alpha$ and PKC- $\beta 2$ were reported as the predominant PKC isoforms expressed in the heart tissue [21]. As an upstream signal, the phosphorylation level of $\mathrm{PKC} \alpha / \beta 2$ was detected in cardiomyocytes incubated by AGE for $7.5,15$, 30, 60 and $120 \mathrm{~min}$. Western blot showed that it could be activated by AGE in a time-dependent manner (Figure 7A). The cells were then co-treated by AGE with the presence of PKC inhibitor GF109203X $(10 \mu \mathrm{M})$, which was added to cells $30 \mathrm{~min}$ before the AGE treatment. We noted that GF109203X could totally abrogate the Cx43 upregulation induced by AGE, while GF109203X alone had no significant effect on Cx43 (Figure 7B). Therefore, the PKC pathway might also be involved in the AGE-induced Cx43 upregulation in cardiomyocytes. 
Figure 7. The involvement of the PKC pathway in the effect of AGE on Cx43 expression. (A) AGE activated the time-dependent phosphorylation of $\mathrm{PKC} \alpha / \beta 2$ in cardiomyocytes assessed by Western blot; (B) Cx43 protein expression in cells treated by AGE for $24 \mathrm{~h}$ with the presence of PKC inhibitor GF109203X (GF, $10 \mu \mathrm{M}) . * p<0.05$ vs. control; Data are mean $\pm \mathrm{SD}$.
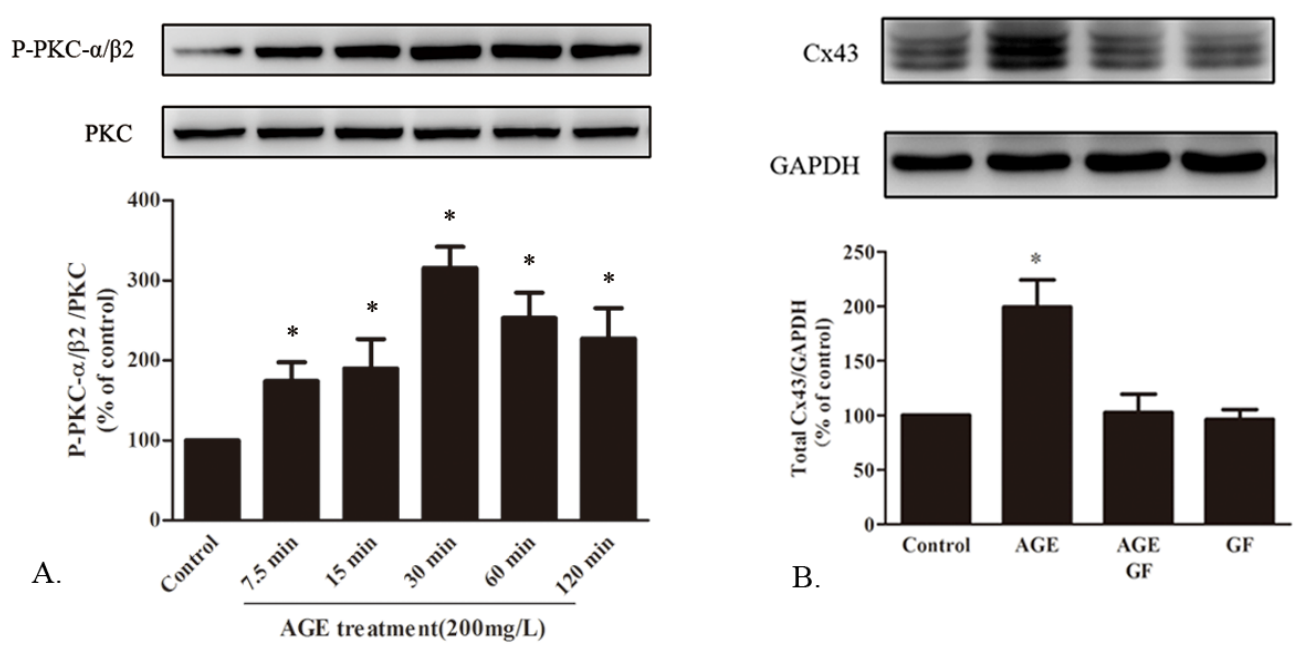

\subsection{Discussion}

Hyperglycemia is an independent risk factor and initiator for cardiac complications in diabetes, which has been reported to cause $\mathrm{Cx} 43$ down-regulation in various tissues, including endothelial cells and cardiomyocytes [7,22]. As a major gap junction protein, reduced Cx43 might affect GJIC function and cardiac conduction velocity, contributing to ventricular tachycardia and other arrhythmias. It would trigger mitochondrial shape change and cytochrome c release [23], finally leading to cell hypertrophy and apoptosis [24,25]. In our previous study, we also reported [6] that high glucose downregulated $\mathrm{Cx} 43$ protein level in neonatal rat cardiomyocytes. But, it still could not explain the discordant results of $\mathrm{Cx} 43$ expression in STZ-induced diabetic rat models [7-9]. There should be other mechanisms of elevating cardiac Cx43 expression in chronic diabetes. Recent evidence implicated that the accumulation of AGE in diabetes contribute to the pathogenesis of cardiovascular diseases $[11,26]$. Its effect on cardiac $\mathrm{Cx} 43$ expression, however, remains unknown.

In the present study, we found that $\mathrm{Cx} 43$ protein redistributed in AGE-infused rat heart and AGE significantly elevated $\mathrm{Cx} 43$ expression both in vivo and in cultured rat cardiomyocytes. The activation of PKC and Erk MAPK pathway might be involved in the mechanism. But, unexpectedly, the increased $\mathrm{Cx} 43$ did not enhance GJIC function.

$\mathrm{Cx} 43$ is the major gap junction protein in cardiomyocytes that mediates the function of cell coupling and leads to orderly electrical conduction [3]. The quantity alteration or redistribution of Cx43 contributes to various arrhythmias in diabetes. Its expression could be regulated at the transcriptional or post-transcriptional levels. Recently, Lin et al. [7] reported that in a three-week STZ-induced diabetic rat model, the total $\mathrm{Cx} 43$ amount and the immunoreactive particles for $\mathrm{Cx} 43$ at the intercalated disks were significantly decreased, but it could be alleviated by either lysosomal (NH4CL, Leupeptin) or proteasomal inhibitor (ALLN), which suggested that diabetes might cause proteolytic degradation of $\mathrm{Cx} 43$. It was consistent with another study [9] demonstrating the reduced 
Cx43 in a diabetic heart. Howarth et al. [8], however, found that in a 12-week diabetic rat model, total and phosphorylated $\mathrm{Cx} 43$ were elevated in ventricular myocytes, leading to prolongation of QRS and QT intervals. Therefore, the results of cardiac Cx43 remodeling still differed, which might be due to the miscellaneous factors in diabetic rat models. In diabetes, high glucose is regarded as a major initiator for cardiac complications. But, it also accelerates the formation and accumulation of AGE, which is the product of nonenzymatic glycoxidation of proteins and participates in various cardiovascular diseases. As high glucose has been previously recognized for its downregulation effect on cardiac $\mathrm{Cx} 43$ [6], the different results of $\mathrm{Cx} 43$ regulation might be partly due to the accumulation of AGE with the development of diabetes, which increased total $\mathrm{Cx} 43$ expression as our present study noticed.

We also demonstrated that AGE elevated both protein and mRNA levels of $\mathrm{Cx} 43$, indicating the transcriptional regulation, which differed from the possible post-transcriptional regulation of high glucose for not changing Cx43 mRNA level [6]. Our results suggested that besides high glucose, AGE might play an important role in cardiac electrical remodeling of diabetes. But, it was not consistent with the results of AGE on Cx43 in other cell lines. It has been demonstrated that in human hepatoma cell line (SKHep1) [27] and human aortic endothelial cells (HAEC) [28], the Cx43 protein was reduced by AGE treatment, while Rubenstein et al. [29] recently reported that AGE did not alter the Cx43 expression in endothelial cells. The different effect of AGE might be partly associated with the treated cell lines; even the proliferation rate differed in AGE-treated SKHep1 and HAEC.

We also noticed that $\mathrm{Cx} 43$ protein scattered and lost orderly distribution between intercalary discs in AGE-infused rat hearts. Recent studies [16,17] have already reported that disorganized connexins were associated with non-functional gap junctions and reduced cell excitability. And the increased lateral $\mathrm{Cx} 43$ was unlikely to enhance intercellular coupling, partly due to the possible dissociation of other junction proteins, such as $N$-cadherin and $\beta$-catenin. Therefore, the $\mathrm{Cx} 43$ upregulation by AGE might further contribute to conduction disturbance in a diabetic heart.

In our study, AGE did not affect the cell viability in neonatal rat cardiomyocytes determined by MTT assay, which was not consistent with the results in other cell lines. Sakata et al. reported that the low dosage of AGE did not produce any change in proliferation of smooth muscle cells (SMCs) at concentrations of up to $20 \mathrm{mg} / \mathrm{L}$, but decreased that of SMCs at $40 \mathrm{mg} / \mathrm{L}$ [30]. In endothelial progenitor cells, co-culturing with AGEs (50-200 mg/L) also inhibited cell proliferation [31]. Another study, however, noticed that AGE accelerated cell proliferation assessed by MTT assay at $200 \mathrm{mg} / \mathrm{L}$ in cardiac fibroblast [32]. Therefore, the unremarkable change in cell viability in our present work might be partly due to the different cell type. But, AGE increased RAGE, the specific receptor for AGE, in a dose- and time-dependent manner and peaked at $200 \mathrm{mg} / \mathrm{L}$ for $24 \mathrm{~h}$. In a 16-week diabetic rat model [33], the atria showed abundant expression of RAGE with diffuse interstitial fibrosis, which could be prevented by administration of an AGE formation inhibitor, OPB-9195. It was consistent with our results in AGE-infused rat heart, indicating RAGE protein upregulation by AGE treatment. But, in AGE-treated cardiomyocytes, RAGE did not show essential change during the first $12 \mathrm{~h}$. In a recent report conducted by Sun et al., they also demonstrated the time- and dose-dependent manner of RAGE expression by AGE treatment in endothelial progenitor cells, while it was only slightly elevated after $12 \mathrm{~h}$ [20]. In another study [34] about the effect of $\mathrm{H}_{2} \mathrm{O}_{2}$ on pancreatic cells, RAGE expression did not change after $6 \mathrm{~h}$ of $\mathrm{H}_{2} \mathrm{O}_{2}$ treatment, but it increased significantly after $24 \mathrm{~h}$. To date, however, few studies mentioned the mechanism of RAGE elevation. It has been reported [35] that the RAGE 
promoter region had three potential NF-kappaB-like and two SP1 binding sites, indicating that RAGE activation might be associated with activation of the NF-kappaB pathway. Inactivated NF-kappaB is a latent form in the cytoplasm, which masks nuclear localization signals. Recently, Zhang et al. demonstrated that exposure of rat neonatal cardiomyocytes to Glycated-BSA $(400 \mathrm{mg} / \mathrm{L})$ increased nuclear NF-kappaB expression consistently after $24 \mathrm{~h}$, which suggested the enhanced translocation of NF-kappaB to nucleus [19]. Therefore, it could be a limitation for the lack of investigation for NF-kappaB expression and its activating time in our study. It might be possible that RAGE acted more as a link to AGE and engaged downstream signal transduction pathways, which in turn upregulated RAGE expression and amplified these cellular effects. Recently, many studies [12-14] focused on the pathogenic effect of AGE-RAGE system in cardiomyocytes. We used siRNA technology to knock down RAGE expression, and it abrogated the upregulation effect of AGE on Cx43. Therefore, AGE might show its effect on cardiac Cx43 by RAGE activation.

Unexpectedly, the cellular gap junction function was not enhanced by AGE treatment. It was believed that function of cardiac gap junction depended on multiple levels involving Cx43 expression, phosphorylation and degradation [36,37]. But, in recent studies, the effect of $\mathrm{Cx} 43$ phosphorylation on cell coupling still differed in various cell types [38,39]. Some findings demonstrated that phosphorylated $\mathrm{Cx} 43$ acted as the main functional form of $\mathrm{Cx} 43$ and dephosphorylation could impair the electrical coupling and signal transmission through gap junction [40-42]. In our study, AGE increased both non-phosphorylation and phosphorylation expression of $\mathrm{Cx} 43$, and the possible mechanism was the activation of the PKC and Erk MAPK pathways. Erk was reported to be critical for cardiac Cx43 upregulation and increased GJIC [43]. However, PKC-induced Cx43 Ser368 phosphorylation resulted in disassembly of the gap junction and reduced channel conductance $[39,44]$, indicating the negative effect of GJIC by PKC activation. It might partly explain the unchanged GJIC function by AGE treatment in spite of $\mathrm{Cx} 43$ upregulation. It was also believed that the phosphorylation sites of $\mathrm{Cx} 43$ could affect their justified location and membrane association. A recent study [7] further pointed out that $\mathrm{Cx} 43$ was redistributed into cell periphery or cytoplasm in diabetes, leading to the suppression of intercellular impulse propagation. Therefore, the AGE-increased Cx43 proteins were possibly unable to assemble properly to exert their activity, which contributed to the unremarkable change of GJIC function.

The present study demonstrated that AGE-RAGE system elevated Cx43 expression both in vitro and in vivo. Further work will still be required to determine the phosphorylation sites of $\mathrm{Cx} 43$ and their corresponding effect in a diabetic heart.

\section{Experimental Section}

\subsection{Chemicals and Reagents}

AGE was prepared by incubating bovine serum albumin (BSA, $50 \mathrm{mg} / \mathrm{mL}$ ) with D-glucose $(0.5 \mathrm{M})$ in phosphate buffered saline (PBS, $0.2 \mathrm{M}, \mathrm{pH} 7.4$ ) for 12 weeks at $37^{\circ} \mathrm{C}$. Unincorporated glucose was dialyzed extensively overnight against PBS. Unmodified BSA was prepared under the same conditions without glucose as a control. As other report described [45], AGE was identified by a fluorescence spectrophotometer (Hitachi, Tokyo, Japan) using a $440 \mathrm{~nm}$ emission wavelength on excitation at $370 \mathrm{~nm}$, which confirmed the higher intensity of AGE in AGE-modified BSA than that in unmodified 
BSA. The AGE solution was filtered to be sterile by $0.22 \mu \mathrm{M}$ Millex GP filter unit (Millipore, Billerica, MA, USA) and confirmed to be endotoxin free $(<2.5 \mu \mathrm{L}$ of endotoxin) by using an endotoxin testing kit (Chromogenic TAL Endpoint Assay Kit, Xiamen, China). Receptor for AGE (RAGE) polyclonal antibody was obtained from Chemicon (Temecula, CA, USA). Monoclonal rabbit antibodies, including anti-Erk, anti-phospho-Erk, anti-JNK, anti-phospho-JNK, anti-p38, anti-phospho-p38 and anti-phospho-PKC $\alpha / \beta 2$, were purchased from Cell Signaling Technology (Boston, MA, USA). PKC polyclonal antibody was obtained from Santa Cruz Biotechnology (Santa Cruz, CA, USA). The corresponding selective inhibitors, including PD98059, SP600125, SB203580 and GF109203X, were obtained from Merck (Darmstadt, Germany). 3-(4,5-dimethylthiazol-2-yl)-2,5-diphenyl-tetrazolium bromide (MTT), Lucifer yellow dye and Cx43 polyclonal antibody were obtained from Sigma (St. Louis, MO, USA). HRP-marked anti-glyceraldehyde-3-phosphate dehydrogenase (GAPDH) antibody was supplied by Kangchen (Shanghai, China).

\subsection{AGE-Infused SD Rat Model}

Male SD rats aged eight weeks and weighed $200 \mathrm{~g}$ were obtained from the experimental animal center of Zhejiang University. Rats were injected intraperitoneally (i.p.) with BSA alone or AGE-BSA at a dosage of $40 \mathrm{mg} / \mathrm{kg} / \mathrm{d}$ for 28 days ( $n=5$ per group) [46,47]. At the end of the experiments, rats were sacrificed, and hearts were collected for immunohistochemisty. Animal procedures were performed according to the Guide for the Care and Use of Laboratory Animals (NIH, revised 1996), and approval was granted by the university ethics review board.

\subsection{Immuohistochemisty}

Hearts were fixed and embedded in paraffin. Samples were then cut into $4-\mu \mathrm{M}$ sections and used for immuohistochemisty study, including RAGE (1:500) and Cx43 (1:2000) staining, respectively. They were followed by incubation with specific HRP-marked second antibodies and DAB (Dojindo, Kumamoto, Japan). After PBS rinsing, samples were counterstained in hematoxylin, dehydrated and mounted. The $\mathrm{Cx} 43$ and RAGE expressions were analyzed by ImageJ $1.43 \mathrm{u}$ software (http://rsb.info.nih.gov/ij) (National institutes of Health, Bethesda, MD, USA).

\subsection{Cell Culture}

Neonatal rat cardiomyocytes were cultured, as we previously described [6]. Briefly, the heart tissue isolated from the heart of 1-2 day old Sprague-Dawley rats (provided by the experimental animal center of Zhejiang University) were dissected and digested in $\mathrm{Ca}^{2+}$ and $\mathrm{Mg}^{2+}$ free PBS containing $0.1 \%$ trypsin and $0.1 \%$ type II collagenase for $10 \mathrm{~min}$ at $37{ }^{\circ} \mathrm{C}$. DMEM cell culture medium (glucose concentration: $5.5 \mathrm{mM}$ ) containing 10\% fetal bovine serum (FBS) was added into the collected cell supernatant to stop the digestive effect of trypsin and collagenase. The above steps were repeated until the tissues were completely digested. The cell suspension was then centrifuged and suspended in DMEM cell culture medium with $10 \% \mathrm{FBS}$ in a humidified $5 \% \mathrm{CO}_{2} / 95 \%$ air atmosphere at $37{ }^{\circ} \mathrm{C}$. The fibroblast in the cell suspension was reduced by pre-plating for $1 \mathrm{~h}$ due to the differential cell adhesion [48] and the addition of 5'-BrdU $(0.01 \mathrm{mM})$ during the first three days to inhibit the growth of fibroblast. 


\subsection{Cell Viability Assay}

Cells were seeded at $2 \times 10^{4}$ cells/well in 96-well culture plates and incubated in serum-free medium for $24 \mathrm{~h}$ before experiment. The cardiomyocytes were then treated with AGE at various concentrations for $24 \mathrm{~h}$ or by various incubation periods. The MTT solution (final concentration, $0.5 \mathrm{mg} / \mathrm{mL}$ ) was added to each well for an additional $4 \mathrm{~h}$ at $37{ }^{\circ} \mathrm{C}$. The supernatants were then removed, followed by $200 \mu \mathrm{L}$ dimethyl sulfoxide (DMSO) added into each well. The absorbance was read at a wavelength of $490 \mathrm{~nm}$. Each independent experiment was repeated five times.

\subsection{Western Blot Assay}

Cells in 6-well plates were harvested and washed with PBS for three times, followed by lysing on ice in $100 \mu \mathrm{L}$ RIPA solution containing $50 \mathrm{mM}$ Tris (pH 7.4), $150 \mathrm{mM} \mathrm{NaCl}, 1 \%$ NP-40, $5 \%$ deoxycholic acid, $0.1 \%$ SDS, $1 \mathrm{mM}$ EDTA, $10 \mathrm{mM} \mathrm{NaF}, 1 \mathrm{mM} \mathrm{Na} \mathrm{VO}_{4}, 1 \mathrm{mM}$ dithiothreitol, $1 \mathrm{mM}$ PMSF, $2 \mu \mathrm{g} / \mathrm{mL}$ leupeptin for $30 \mathrm{~min}$. Proteins were quantified with the Bio-Rad DC Protein Assay Kit II (Bio-Rad, Hercules, CA, USA). Samples containing equal amounts of protein were run on a $10 \%$ tris-glycine gradient gel, transferred to PVDF membranes and blocked for $1 \mathrm{~h}$ with $5 \%$ nonfat milk in TBST (Tris-buffered solution containing $0.1 \%$ Tween 20) at room temperature. Membranes were then soaked with primary antibodies overnight at $4{ }^{\circ} \mathrm{C}$ followed by secondary antibody incubation for $1 \mathrm{~h}$ at room temperature. Finally, the membranes were reacted with enhanced chemiluminescence (ECL) reagents and exposed by Image Quant LAS-4000 (Fujifilm, Tokyo, Japan). Band densities were determined by an image Multi-Gauge Software (Fujifilm, Tokyo, Japan). Each experiment was repeated at least 3 times.

\subsection{Real-Time Reverse Transcription-PCR (Real-Time RT-PCR)}

TRIZOL reagent (Invitrogen, Carlsbad, CA, USA) was used to isolate total RNA, which was converted into cDNA by murine leukemia virus reverse transcriptase (Promega, Mannheim, Germany). The primers for amplification of specific rat mRNA were as follows: $\mathrm{Cx} 43$ (116 bp), 5'-TCTGCCTTTCGCTGTAACACT-3' and 5'-GGGCACAGACACGAATATGAT-3'; RAGE (139 bp), 5'-CAGGGTCACAGAAACCGG-3' and 5'-ATTCAGCTCTGCACGTTCCT-3'; GAPDH (152 bp), 5'-ATTCTCCCACGGCAAGTT-3' and 5'-CGCCAGTAGACTCCACGACATA-3' (sense and antisense, respectively). Real-time PCR was performed on the ABI 7500 cycler (Applied Biosystems, CA, USA) using SYBR Premix Ex Taq reagent (Takara, Shiga, Japan). The relative amount of target gene expression was normalized by GAPDH as an internal control.

\subsection{Scrape Loading Dye Transfer Assay}

The function of gap junctional intercellular communication (GJIC) was assessed by scrape loading dye transfer assay as previously described. Cells cultured in $35 \mathrm{~mm}$ dishes were incubated in preheated $\left(37{ }^{\circ} \mathrm{C}\right) 1 \%$ Lucifer Yellow dye solution (dissolved in $\mathrm{Ca}^{2+}$ and $\mathrm{Mg}^{2+}$ free PBS) after they were rinsed with warm PBS $\left(37^{\circ} \mathrm{C}\right)$. A surgical blade was used to make scrape lines through the cell monolayer. After $3 \mathrm{~min}$, the dye solution was removed. The cells were rinsed with PBS and fixed by 4\% paraformaldehyde for $1 \mathrm{~min}$. The distance of the dye transferred from the scraped margin was observed with an inverted fluorescent microscope. 


\subsection{Small Interference RNA Transfection}

Small interfering RNA molecules (siRNA) were designed by GenePharma (Shanghai, China). The siRNA (Up: 5'-GCUAGAAUGGAAACUGAACTT-3'; Down: 5'-GUUCAGUUUCCAUUCUAGCTT-3') targeted at RAGE mRNA were used to knock down the expression of RAGE. A scrambled siRNA (Up: 5'-UUCUCCGAACGUGUCACGUTT-3'; Down: 5'-ACGUGACACGUUCGGAGAATT-3') was designed as a negative control. The siRNA diluted in Hiperfect transfection reagent (Qiagen, Hilden, Germany) was premixed with serum- and antibiotic-free DMEM medium at room temperature for $10 \mathrm{~min}$. Then, the cells in 6-well plates were incubated with $500 \mu \mathrm{L}$ mixed solution containing $100 \mathrm{nM}$ siRNA, followed by additional $500 \mu \mathrm{L}$ culture medium after $4 \mathrm{~h} .24 \mathrm{~h}$ later, the culture medium was replaced by DMEM medium with penicillin/streptomycin and 10\% FBS. Experiments were carried out $48 \mathrm{~h}$ after completion of the transfection.

\subsection{Statistical Analysis}

Results were expressed as mean \pm SEM. for at least three individual experiments. Statistical analysis between groups was performed by one-way ANOVA. The level of $p<0.05$ was considered statistically significant.

\section{Conclusions}

In conclusion, the present study demonstrated that AGE-RAGE system elevated Cx43 expression both in vitro and in vivo. The phosphorylation of the PKC and Erk MAPK pathways were involved in this process. The increased $\mathrm{Cx} 43$ expression did not enhance cellular coupling, and they also lost orderly distribution along intercalary discs in vivo models, which might contribute to electrical remodeling in a diabetic heart. Further work will still be required to investigate the phosphorylation sites of $\mathrm{Cx} 43$ and the possible $\mathrm{Cx} 43$ redistribution in cultured cardiomyocytes.

\section{Acknowledgments}

We thank the Biomedical Research Center in Sir Run Run Shaw Hospital, College of Medicine, Zhejiang University, for the use of test instruments and equipment.

\section{References}

1. Howarth, F.C.; Shafiullah, M.; Adeghate, E.; Ljubisavljevic, M.; Jacobson, M. Heart rhythm disturbances in the neonatal alloxan-induced diabetic rat. Pathophysiology 2011, 18, 185-192.

2. Shaw, R.M.; Rudy, Y. Ionic mechanisms of propagation in cardiac tissue. Roles of the sodium and L-type calcium currents during reduced excitability and decreased gap junction coupling. Circ. Res. 1997, 81, 727-741.

3. Kleber, A.G.; Rudy, Y. Basic mechanisms of cardiac impulse propagation and associated arrhythmias. Physiol. Rev. 2004, 84, 431-488.

4. Vozzi, C.; Dupont, E.; Coppen, S.R.; Yeh, H.I.; Severs, N.J. Chamber-related differences in connexin expression in the human heart. J. Mol. Cell. Cardiol. 1999, 31, 991-1003. 
5. Das Evcimen, N.; King, G.L. The role of protein kinase $\mathrm{C}$ activation and the vascular complications of diabetes. Pharmacol. Res. 2007, 55, 498-510.

6. Yu, L.; Zhao, Y.; Fan, Y.; Wang, M.; Xu, S.; Fu, G. Epigallocatechin-3 gallate, a green tea catechin, attenuated the downregulation of the cardiac gap junction induced by high glucose in neonatal rat cardiomyocytes. Cell. Physiol. Biochem. 2010, 26, 403-412.

7. Lin, H.; Ogawa, K.; Imanaga, I.; Tribulova, N. Remodeling of connexin 43 in the diabetic rat heart. Mol. Cell. Biochem. 2006, 290, 69-78.

8. Howarth, F.C.; Chandler, N.J.; Kharche, S.; Tellez, J.O.; Greener, I.D.; Yamanushi, T.T.; Billeter, R.; Boyett, M.R.; Zhang, H.; Dobrzynski, H. Effects of streptozotocin-induced diabetes on connexin43 mRNA and protein expression in ventricular muscle. Mol. Cell. Biochem. 2008, 319, 105-114.

9. Stilli, D.; Lagrasta, C.; Berni, R.; Bocchi, L.; Savi, M.; Delucchi, F.; Graiani, G.; Monica, M.; Maestri, R.; Baruffi, S.; et al. Preservation of ventricular performance at early stages of diabetic cardiomyopathy involves changes in myocyte size, number and intercellular coupling. Basic Res. Cardiol. 2007, 102, 488-499.

10. Brownlee, M. Biochemistry and molecular cell biology of diabetic complications. Nature 2001, 414, 813-820.

11. Candido, R.; Forbes, J.M.; Thomas, M.C.; Thallas, V.; Dean, R.G.; Burns, W.C.; Tikellis, C.; Ritchie, R.H.; Twigg, S.M.; Cooper, M.E.; et al. A breaker of advanced glycation end products attenuates diabetes-induced myocardial structural changes. Circ. Res. 2003, 92, 785-792.

12. Shang, L.; Ananthakrishnan, R.; Li, Q.; Quadri, N.; Abdillahi, M.; Zhu, Z.; Qu, W.; Rosario, R.; Toure, F.; Yan, S.F.; et al. RAGE modulates hypoxia/reoxygenation injury in adult murine cardiomyocytes via JNK and GSK-3beta signaling pathways. PLoS One 2010, 5, e10092.

13. Petrova, R.; Yamamoto, Y.; Muraki, K.; Yonekura, H.; Sakurai, S.; Watanabe, T.; Li, H.; Takeuchi, M.; Makita, Z.; Kato, I.; et al. Advanced glycation endproduct-induced calcium handling impairment in mouse cardiac myocytes. J. Mol. Cell. Cardiol. 2002, 34, 1425-1431.

14. Ma, H.; Li, S.Y.; Xu, P.; Babcock, S.A.; Dolence, E.K.; Brownlee, M.; Li, J.; Ren, J. Advanced glycation endproduct (AGE) accumulation and AGE receptor (RAGE) up-regulation contribute to the onset of diabetic cardiomyopathy. J. Cell. Mol. Med. 2009, 13, 1751-1764.

15. Ripplinger, C.M.; Li, W.; Hadley, J.; Chen, J.; Rothenberg, F.; Lombardi, R.; Wickline, S.A.; Marian, A.J.; Efimov, I.R. Enhanced transmural fiber rotation and connexin 43 heterogeneity are associated with an increased upper limit of vulnerability in a transgenic rabbit model of human hypertrophic cardiomyopathy. Circ. Res. 2007, 101, 1049-1057.

16. Rucker-Martin, C.; Milliez, P.; Tan, S.; Decrouy, X.; Recouvreur, M.; Vranckx, R.; Delcayre, C.; Renaud, J.F.; Dunia, I.; Segretain, D.; et al. Chronic hemodynamic overload of the atria is an important factor for gap junction remodeling in human and rat hearts. Cardiovasc. Res. 2006, 72, 69-79.

17. Nygren, A.; Olson, M.L.; Chen, K.Y.; Emmett, T.; Kargacin, G.; Shimoni, Y. Propagation of the cardiac impulse in the diabetic rat heart: Reduced conduction reserve. J. Physiol. 2007, 580, 543-560.

18. De Mello, W.C. Impaired cell communication in the diabetic heart. The role of the renin angiotensin system. Mol. Cell. Biochem. 2007, 296, 53-58. 
19. Zhang, M.; Kho, A.L.; Anilkumar, N.; Chibber, R.; Pagano, P.J.; Shah, A.M.; Cave, A.C. Glycated proteins stimulate reactive oxygen species production in cardiac myocytes: Involvement of Nox2 (gp91phox)-containing NADPH oxidase. Circulation 2006, 113, 1235-1243.

20. Sun, C.; Liang, C.; Ren, Y.; Zhen, Y.; He, Z.; Wang, H.; Tan, H.; Pan, X.; Wu, Z. Advanced glycation end products depress function of endothelial progenitor cells via p38 and ERK 1/2 mitogen-activated protein kinase pathways. Basic Res. Cardiol. 2009, 104, 42-49.

21. Giles, T.D.; Ouyang, J.; Kerut, E.K.; Given, M.B.; Allen, G.E.; McIlwain, E.F.; Greenberg, S.S. Changes in protein kinase $\mathrm{C}$ in early cardiomyopathy and in gracilis muscle in the $\mathrm{BB} / \mathrm{Wor}$ diabetic rat. Am. J. Physiol. 1998, 274, H295-H307.

22. Fernandes, R.; Girao, H.; Pereira, P. High glucose down-regulates intercellular communication in retinal endothelial cells by enhancing degradation of connexin 43 by a proteasome-dependent mechanism. J. Biol. Chem. 2004, 279, 27219-27224.

23. Trudeau, K.; Muto, T.; Roy, S. Downregulation of mitochondrial connexin 43 by high glucose triggers mitochondrial shape change and cytochrome $\mathrm{C}$ release in retinal endothelial cells. Invest. Ophthalmol. Vis. Sci. 2012, 53, 6675-6681.

24. Liu, L.; Hu, X.; Cai, G.Y.; Lv, Y.; Zhuo, L.; Gao, J.J.; Cui, S.Y.; Feng, Z.; Fu, B.; Chen, X.M. High glucose-induced hypertrophy of mesangial cells is reversed by connexin 43 overexpression via PTEN/Akt/mTOR signaling. Nephrol. Dial. Transplant. 2012, 27, 90-100.

25. Li, A.F.; Roy, S. High glucose-induced downregulation of connexin 43 expression promotes apoptosis in microvascular endothelial cells. Invest. Ophthalmol. Vis. Sci. 2009, 50, 1400-1407.

26. Bidasee, K.R.; Zhang, Y.; Shao, C.H.; Wang, M.; Patel, K.P.; Dincer, U.D.; Besch, H.R., Jr. Diabetes increases formation of advanced glycation end products on Sarco(endo)plasmic reticulum $\mathrm{Ca}^{2+}$-ATPase. Diabetes 2004, 53, 463-473.

27. Lin, F.L.; Chang, C.I.; Chuang, K.P.; Wang, C.Y.; Liu, H.J. Advanced glycation end products down-regulate gap junctions in human hepatoma SKHep 1 cells via the activation of Src-dependent ERK1/2 and JNK/SAPK/AP1 signaling pathways. J. Agric. Food Chem. 2010, 58, 8636-8642.

28. Wang, C.Y.; Liu, H.J.; Chen, H.J.; Lin, Y.C.; Wang, H.H.; Hung, T.C.; Yeh, H.I. AGE-BSA down-regulates endothelial connexin43 gap junctions. BMC Cell Biol. 2011, 12, 19.

29. Rubenstein, D.A.; Maria, Z.; Yin, W. Glycated albumin modulates endothelial cell thrombogenic and inflammatory responses. J. Diabetes Sci. Technol. 2011, 5, 703-713.

30. Sakata, N.; Meng, J.; Takebayashi, S. Effects of advanced glycation end products on the proliferation and fibronectin production of smooth muscle cells. J. Atheroscler. Thromb. 2000, 7, 169-176.

31. Chen, J.; Song, M.; Yu, S.; Gao, P.; Yu, Y.; Wang, H.; Huang, L. Advanced glycation endproducts alter functions and promote apoptosis in endothelial progenitor cells through receptor for advanced glycation endproducts mediate overpression of cell oxidant stress. Mol. Cell. Biochem. 2010, 335, 137-146.

32. Li, J.; Liu, N.F.; Wei, Q. Effect of rosiglitazone on cardiac fibroblast proliferation, nitric oxide production and connective tissue growth factor expression induced by advanced glycation end-products. J. Int. Med. Res. 2008, 36, 329-335.

33. Kato, T.; Yamashita, T.; Sekiguchi, A.; Tsuneda, T.; Sagara, K.; Takamura, M.; Kaneko, S.; Aizawa, T.; Fu, L.T. AGEs-RAGE system mediates atrial structural remodeling in the diabetic rat. J. Cardiovasc. Electrophysiol. 2008, 19, 415-420. 
34. Kang, R.; Tang, D.; Livesey, K.M.; Schapiro, N.E.; Lotze, M.T.; Zeh, H.J., III. The Receptor for Advanced Glycation End-products (RAGE) protects pancreatic tumor cells against oxidative injury. Antioxid. Redox. Signal. 2011, 15, 2175-2184.

35. Li, J.; Schmidt, A.M. Characterization and functional analysis of the promoter of RAGE, the receptor for advanced glycation end products. J. Biol. Chem. 1997, 272, 16498-16506.

36. Duffy, H.S.; Ashton, A.W.; O’Donnell, P.; Coombs, W.; Taffet, S.M.; Delmar, M.; Spray, D.C. Regulation of connexin43 protein complexes by intracellular acidification. Circ. Res. 2004, 94, 215-222.

37. Leithe, E.; Rivedal, E. Epidermal growth factor regulates ubiquitination, internalization and proteasome-dependent degradation of connexin43. J. Cell. Sci. 2004, 117, 1211-1220.

38. Jia, G.; Cheng, G.; Gangahar, D.M.; Agrawal, D.K. Involvement of connexin 43 in angiotensin II-induced migration and proliferation of saphenous vein smooth muscle cells via the MAPK-AP-1 signaling pathway. J. Mol. Cell. Cardiol. 2008, 44, 882-890.

39. Liang, J.Y.; Wang, S.M.; Chung, T.H.; Yang, S.H.; Wu, J.C. Effects of 18-glycyrrhetinic acid on serine 368 phosphorylation of connexin43 in rat neonatal cardiomyocytes. Cell. Biol. Int. 2008, 32, 1371-1379.

40. Musil, L.S.; Cunningham, B.A.; Edelman, G.M.; Goodenough, D.A. Differential phosphorylation of the gap junction protein connexin43 in junctional communication-competent and -deficient cell lines. J. Cell. Biol. 1990, 111, 2077-2088.

41. Kwak, B.R.; Jongsma, H.J. Regulation of cardiac gap junction channel permeability and conductance by several phosphorylating conditions. Mol. Cell. Biochem. 1996, 157, 93-99.

42. Beardslee, M.A.; Lerner, D.L.; Tadros, P.N.; Laing, J.G.; Beyer, E.C.; Yamada, K.A.; Kleber, A.G.; Schuessler, R.B.; Saffitz, J.E. Dephosphorylation and intracellular redistribution of ventricular connexin43 during electrical uncoupling induced by ischemia. Circ. Res. 2000, 87, 656-662.

43. Polontchouk, L.; Ebelt, B.; Jackels, M.; Dhein, S. Chronic effects of endothelin 1 and angiotensin II on gap junctions and intercellular communication in cardiac cells. FASEB J. 2002, 16, 87-89.

44. Huang, Y.S.; Tseng, Y.Z.; Wu, J.C.; Wang, S.M. Mechanism of oleic acid-induced gap junctional disassembly in rat cardiomyocytes. J. Mol. Cell. Cardiol. 2004, 37, 755-766.

45. Zhang, F.L.; Gao, H.Q.; Shen, L. Inhibitory effect of GSPE on RAGE expression induced by advanced glycation end products in endothelial cells. J. Cardiovasc. Pharmacol. 2007, 50, 434-440.

46. Zheng, F.; Cai, W.; Mitsuhashi, T.; Vlassara, H. Lysozyme enhances renal excretion of advanced glycation endproducts in vivo and suppresses adverse age-mediated cellular effects in vitro: A potential AGE sequestration therapy for diabetic nephropathy? Mol. Med. 2001, 7, 737-747.

47. Bierhaus, A.; Schiekofer, S.; Schwaninger, M.; Andrassy, M.; Humpert, P.M.; Chen, J.; Hong, M.; Luther, T.; Henle, T.; Kloting, I.; et al. Diabetes-associated sustained activation of the transcription factor nuclear factor-kappaB. Diabetes 2001, 50, 2792-2808.

48. Blondel, B.; Roijen, I.; Cheneval, J.P. Heart cells in culture: A simple method for increasing the proportion of myoblasts. Experientia 1971, 27, 356-358.

(C) 2013 by the authors; licensee MDPI, Basel, Switzerland. This article is an open access article distributed under the terms and conditions of the Creative Commons Attribution license (http://creativecommons.org/licenses/by/3.0/). 